International Journal of Instruction e-ISSN: 1308-1470 • www.e-iji.net

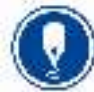

April 2021 • Vol.14, No.2

p-ISSN: 1694-609X

pp. 1051-1072

Article submission code 20200516130656

Received: $16 / 05 / 2020$

Revision: $17 / 11 / 2020$
Accepted: 08/12/2020

OnlineFirst: 25/03/2021

\title{
On the Communicative Functions of Context in Foreign Language Education
}

\section{Krzysztof Polok}

Assoc. Prof. University of Bielsko-Biala, Poland, sworntran@interia.pl

The paper is basically a meta-analysis of the topic indicated in the title. It expounds the notion of context as an integral component in the process of teaching communication. In making an attempt to comprehend and subsequently produce a message, inevitably, it is the cohesive grasp of context that determines the rate of success in attempts to organize and sketch the process of communication one is about to take part in. Taking into account the theories offered by Cummins (1984b/2008), as well as the critical analysis offered by Baker (1996) and Song (2010), this paper indicates both the function context performs in the process of interaction organization and the position it is usually ascribed in FL education. Finally, an attempt to analyse, explain and briefly summarize the importance of appropriate FL teaching methods and presentation of context to foreign language learners is discussed.

Keywords: context, foreign language education (FLE), language codes, basic interpersonal communication skills (BICS), cognitive/academic language proficiency

\section{INTRODUCTION}

When browsing a course-book unit, one can discover that at least two various types of language - or codes, as Bernstein (1971), or later Levine (2010) call them - are being offered to the learners; on the one hand, in dialogues (which usually begin a unit), where everyday language containing simple statements are presented; on the other hand, in course-book reading texts (which, as a rule, follow the dialogues), a more refined form of language communication, compound and complex forms, are shown ${ }^{1}$. Regardless, however, whether it is the first, or the second type of code that is being used, what matters in both cases is the context in which the information placed in any of the two types of communication is rendered. An experienced teacher, when asked, will often produce a remark that the learners, who usually have problems with the appropriate allocation of context in a given text, are usually regarded as making much less progress in general over-all assessment of linguistic performance.

\footnotetext{
${ }^{1}$ The very expression 'code' was originally used by Bernstein (1971) who used the expressions restricted and elaborated codes respectively here.

Citation: Polok, K. (2021). On the Communicative Functions of Context in Foreign Language Education. International Journal of Instruction, 14(2), 1051-1072. https://doi.org/10.29333/iji.2021.14260a
} 
It is obvious that one of the most important aspects of assessment of TL (target language) skills is the level of proper context ${ }^{2}$ recognition that often depends on internal/external fluency in the manipulation of various sentence patterns. In other words, the more skillful in fast recognition of various structures (of both vocabulary and grammar type) one is, the less time is needed to discover and, subsequently, follow the context to the intended meaning hidden in a sentence. Such differences are easily noticed when research in reading comprehension is carried out. Ruedel, Brann, Gray \& Zorfass (2013) specify the following helpful tips concerning context in a sentence, or passage: /1/ knowledge of word roots and/or word affixes; /2/ knowledge of grammatical constructions; /3/ skill in the discovery of contrasting techniques used in a language; /4/ knowledge of basic word meanings; appropriate use of logics; and - last, but not least,/5/ knowledge of the illustrative figures that exist in the language.

The issue of context discovery in a spoken text is much more difficult. Following Liu's (2015) elaboration of Kramsch's (2003) concepts, in addition to all the suggestions specified above there is also the ability to recognize various culture-orientated nonlinguistic signs, customarily applied by the native users of a language. Tone, accurately produced melody of an expression, or appropriately and carefully placed stress, as well as facial expressions and/or body movements perform an important and often indispensible function in the discovery of the context hidden in a sentence or text. A listener, when appropriately trained in the discovery of one, or more of the clues mentioned above, will undoubtedly find it easier to approach, select and correctly follow the context of a sentence or text ${ }^{3}$.

However, a situation deduced not only by Bernstein (1971), and later elaborated by Polok (2018), but also by a number of other researchers (Baker,1997; Cummins, 1984; Acton,1979, Halbach, 2003, Cummins, 2008, Garside, 2019 and others), states that in many cases the context of such spoken sentences/texts is reduced, whereas in some others more developed. In other words, what clearly marks context visibility in spoken texts (assuming that the level of context visibility in written, unillustrated texts is almost always the same) is not only the type of text itself, but also the conditions in which the said text is presented to its receivers. When a received statement belongs to what is labelled as everyday communication and has been presented with the help of many

\footnotetext{
${ }^{2}$ As the expression 'context' may raise problems as far as its definition goes, the following two definitions of context are to be observed in the paper: /1/ the parts of a written or spoken statement that precede or follow a specific word or passage, usually influencing its meaning or effect; in case textual context is being referred to; and $/ 2 /$ the set of circumstances or facts that surround a particular event, situation, etc. in case a language class-room situation is being discussed. Both definitions after: http://www.dictionary.com/browse/context (Accessed: 21.02.2018)

${ }^{3}$ Kramsch (2003), observing close co-existence between context and culture, proposes six different parts of context: linguistic context, cultural context, interactional context, situational context, immediate situational context ans contextual context. At the same time, Song (2010) offers a little bit simplified division, spliting context into linguistic context, situational context and cultural context.
} 
context embedded attributes specified above, a message receiver has a much greater chance to discover, and closely follow its content (and, subsequently, understand the message). However, when the same message has been presented in a much contextreduced situation, the receiver's possibilities of grasping the meaning correctly are greatly diminished. The learner is mostly left to him/herself and has to make use of the language-related elements of knowledge $\mathrm{h} / \mathrm{s}$ managed to internalize earlier.

A good example of such a context-reduced situation is a task the language learner might take part in during listening comprehension classes. Practically speaking, a learner is expected to grasp the meaning of a message on the grounds of his/her level of listening proficiency, the only elements $\mathrm{h} / \mathrm{s}$ has to base upon are those which $\mathrm{h} / \mathrm{s}$ had managed to internalize earlier, i.e. while studying/learning the language contained in the message (see the conclusions drawn from the research done by Kłębowska (2002), for example). Consequently, at the moment of message reception $\mathrm{h} / \mathrm{s}$ has to search for languagespecific knowledge and retrieve all the information concerning the language-specific syntactic rules, as well as the rules describing the forms of vowel/consonant pronunciation found in the aural exercise. It is also worth noticing that any of the rules or regulations that may appear valid here, which have not been duly internalized by a learner, may make the whole process of context search impossible to complete. Obviously, many learners may make an attempt to guess at the meaning of the missing information, so as to successfully complete the message search, and in some cases they might even be lucky enough to succeed, but this form of educational behavior has little to do with appropriate organization of the learner's educational processing. What quite often happens, and what has been presented by Norman (1980) and developed by Connor et al. (2008) as one of their key research conclusions, is the iceberg model syndrome. This constructivist description of a learner's wanderings to logically understand the message delivered by the teacher, closely illustrates what occurs in the learner's mind when $\mathrm{h} / \mathrm{s}$ has not been able to aptly grasp the on-going information hidden in the listening task. Had the learner not been able to smoothly cover any of the task hidden ideas, h/s would most probably not be able to fully comprehend most of the remaining contents of the lesson; when such a situation has not been successfully addressed by the teacher, in very many cases the learner has just begun on his/her way to disliking the subject. It is at these moments as well, that a learner's level of objective self-awareness, as Duval \& Wicklund (1972) call this psychological phenomenon grows, thus pushing him/her closer to define and describe his/her current negative state of mind (Bieńkowska \& Polok, 2020).

\section{METHOD}

A similar observation, albeit from a totally different perspective, can be found in Cummins' hypothesis of a learner's developmental interdependence. Generally interested in the issues concerning the reasons for better/worse levels of L2 proficiency, Cummins (1984, developed in Cummins, 2008) analyses possible means of language register, be it L1 or L2, and finds that there are two registers of language people (L2 learners included) deal with and that these are clearly different. Without going into details of this quite interesting observation, Cummins focuses upon an assertion partly 
related to what has already been presented above, taking into account the fact that modern languages possess the two codes necessary to faultlessly carry out communication, raises a claim that one of the reasons which can help to explain evident differences in the learners' level of L2 proficiency could be the actual level of L1 proficiency a learner possesses. In other words, the higher the actual L1 proficiency level is, the higher L2 proficiency is likely to be.

Another issue postulated by Cummins (1984/2008), while analyzing a learner's approach to language in general concerns the types - or codes, as Levine (2010) calls them - of language needed to effectively participate in various communication-requiring instances, is based upon the stance that what primarily matters in communication is appropriately correct discovery of context. In one of his later works, Cummins (2008) not only declares that the forms of context-containing situations differ depending on the situation in a given message, but also that there are differences between the types of code needed for successful communication to finally be completed. Moving along with the train of thought found in Bernstein's theory (1980), who paid little attention to context as such, but to the type of code needed to communicate in various life-contained situations, Cummins (2008) also states that people, do not only need a different code, but also a different skill ${ }^{4}$, in order to attain success in everyday communication ${ }^{5}$. Naturally, the sources where said code as described by Bernstein (1980), or Levine (2010), or a skill as Cummins $(1984,2008)$ sees it, are similar in the two researchers' descriptive analyses and these can be found to have been functioning as far back as the beginnings of human language. This is mostly why Cummins (1984 and 2008) proposes two names to closely describe each of the communication-requiring situations: indispensable skills which are necessary to effectively carry out various forms of dayto-day communication were labeled basic interpersonal communication skills (BICS), whereas those which are generally used to produce opinions and/or evaluations were described as various forms of cognitive/academic language proficiency (CALP). As Cummins (2008) was mostly interested in the ways which conditioned success in human communication, and one of the conditioning aspects was recognized to be closely related to successful search for context in a message, his hypothesis was mainly based upon the issue of ease or difficulty in finding and making use of context. Consequently, this is the reason why the two opposite poles in the entire ongoing process of communication deliverance proposed in Cummins' hypothesis are labeled as either context-embedded or context-reduced. The former is considered to be closely connected with various BICS-related moments expressing people's daily activity whereas the latter, i.e. the one where the degree of context is notably reduced, can be found in various academic and/or cognition-requiring situations.

Not only are the Cummins $(1984,2008)$ theories connected to various L2 learning activities, referring to situations which help one discover the difference between

\footnotetext{
${ }^{4}$ Cummins (1984) understands skill as a level of skillful proficiency used when producing a message.

${ }^{5}$ A similar approach can be found in Liu (2015).
} 
classroom activities that are based upon general (surface) knowledge but also to the activities which delve deeper and expect L2 learners to make use of cognitive abilities. Although Cummins does not offer a ready-made recipe as to which lesson activities are to be considered surface-like and which go deeper and expect L2 learners to engage their cognitive potential, it may be hypothesized that the activities requiring cognitive involvement usually belong to higher order thinking skills (HOTS), whereas the surface types do not reach the depth of (HOTS) or go beyond a superficial border (Anderson \& Krathwohl, 2001). Baker (1997), following Cummins (1984), agrees that the image of an iceberg mentioned earlier reveals its didactic potential here. While analyzing the difference between HOTS and LOTS, one can plainly see that such L2 didactic activities like text comprehension, appropriate application of grammar and/or vocabulary, correct pronunciation of words or even appropriate syntactic application of specifically selected words/phrases largely follow LOTS-requiring classroom situations ${ }^{6}$. Whereas those labeled as cognitive/academic proficiency skills by Baker (1997), entail HOTS-related forms of educational performance which require the learners to reveal semantic and/or functional potential.

Keeping in mind the descriptive differences presented above, both BICS and CALPrelated activities, when introduced to L2 school learners, must observe a number of educationally important issues. First of all, in contrast to LOTS, where the supportive context is always at hand, many HOTS-including activities usually operate in contextreduced environments. Any such activity must sensitize the L2 learners to any whatsoever, not only external (where they can find just a little bit of help), but mostly internal pieces of additional information, as to where and how to search for the message embedded context. Depending on the internalized amount of context-referring information L2 learners actually possess, their search for context will in turn be more or less successful. Here, again, Krashen's (1981) claim, as to the importance of comprehensible input when introducing a text/ message during an L2 lesson, appears to be a helpful hint to all less experienced L2 teachers ${ }^{7}$.

The notion of deliberately planned, well measured introduction of comprehensible input is, however, not the only issue that has to be considered when aiding L2 learners in efforts to discover largely reduced context in the messages received. The other issue appears to be appropriate distribution of LOTS and HOTS-related activities during an L2 lesson. As clearly specified in a book by Repka \& Šipošova (2017), any process of foreign language (further FL) education must always include attentive and on-going scrupulous evaluation as to one's current level of TL proficiency, because skill cannot precede the learner-based amount of knowledge that refers to linguistic aptitude. In other words, any planned form of L2-excelling activity has to take under consideration the current level of the L2 learners linguistic abilities, which as it seems, is to be recognized as the borderline of their educational capabilities. Thus, any L2 task, regardless of whether its aim is to practice LOTS or HOTS, that surpasses the current

\footnotetext{
${ }^{6}$ In his book, Baker (1997, p. 152) calls them 'conversational proficiency' activities.

${ }^{7}$ The idea was later discussed and explicated in Krashen-Brown-ALP (2007).
} 
level $(+1)$ of a learner's L2 proficiency, is likely to be received by the learners as either too difficult or too complicated and, ultimately, be cast away.

Needless to say, although the BICS/CALP distinction seems to be useful, (mostly for various analytical purposes), it has to be remembered that there is actually no empirical evidence to decide (and/or discover) where the real border between the two items is. Baker (1997), for example, states that, generally, CALP-related abilities often border culture-specific types of literacy, which might result in the appearance of various on-thespot problematic difficulties. Thus, due to the imprecise nature of both BICS and CALP notions, these issues may present the on-going reality in a clearly oversimplified manner. Apart from that, it has to be noted that L2 development cannot be perceived as static and uninfluenced by many other, suddenly appearing, impulses (such as motivation, for example) which, in turn, means that the whole process of mutual coexistence of conversational and academic proficiency is never to be perceived as external, but rather as an internal one. Although it is true that L2 education generally begins with various exercises allowing a learner to practice L2 within a LOTS-related area, many of the latest course-books rightly ascertain that HOTS aspects are never far behind and students (both adults and children) should be encouraged to express their own organization of language used for message exchange.

\section{FINDINGS}

As specified above, both BICS and CALP-related activities are to be included into the design of an FL lesson. Cummins (2008) proposes that any L2 lesson design has to contain both cognitively demanding, as well as far less demanding forms of communication to be approved of by its participants. When these situations have been juxtaposed with the two context-observing forms of communication-practicing activities, i.e. a context-embedded as well as a context-reduced one, four independent quadrants ready to contain any of the skill-practicing tasks will appear. The following quadrants should ultimately be of help in developing any of the two forms of linguistic activities of BICS and CALP nature: /a/ context-embedded communication, carried out within cognitively undemanding forms of talk (for example, informing L2 learners about the lesson topic, which can be given in the form of instruction about the page they are to open their books on); /b/ context-embedded communication, carried out within cognitively demanding forms of talk (for example, an FL autonomy-strengthening teacher-learner talk, as to what tasks are to be included in the term syllabus); /c/ contextreduced communication, carried out within cognitively undemanding forms of talk (for example, oral explanation how to successfully compete a given task); and, finally, /d/ context-reduced communication, carried out within cognitively demanding forms of communication (for example, a talk on a carefully selected, psychologically/ socially salient topic held between the teacher and learners). In each case, the learners have to confront a different context-searching technique, necessary for a message-embedded or 
message-reduced context discovery, in this way learning about the forms of context search is imperative for context recognition ${ }^{8}$.

As proposed by Bentley (2010), what undoubtedly matters in each case are the lesson deliverance techniques applied by the FL teacher. One of the most popular FL teaching/learning techniques is the one labelled frontal. It seems to be one of the most common forms of message transmission, not only because it often does not require much preparation on the part of a teacher, but also because it generally goes along with and satisfies many learners' ideas of an appropriately delivered school lesson. On the whole, the frontal teaching technique is liked and approved of by the learners, as it usually covers plenty of context-embedded information. The teacher either presents various lecture-like lessons, with plenty of different forms of pictorial (and body language) demonstration included (especially, when the Power-Point technique has been selected), or offers some other forms of classroom involvement, where it is quite easy to discover and/or follow the context. This can be carried out in many ways: either as a direct option (when the teacher demonstrates, talks, draws, explains etc. thus making use of a variety of non-verbal messages closely tuned with verbal information), or as an easily detected form of indirect option (when the learners are requested to read, watch, or even listen to various stories), most often assisted and supported with the teacher's apt and immediate help. In both cases the context-providing part is performed by the teacher, whereas the part that is to receive the context (as faultlessly as possible) are the learners. Most of the time the class remains within various LOTS-like activities, being expected to understand the information, surface-digest it and, make use of the obtained knowledge by applying it in a number of easy, largely reproductive, exercises. As the teacher usually does quite a lot to simplify the delivered information as much as possible, many of the learners follow the lesson in a relatively comprehensible way. However, what may sound worrying in such a situation is that many of the learners participating in the lesson have been given a misguided, not to say a false, idea of what context-search activities should be like and how much effort is needed to succeed. As a result, it may be claimed that LOTS-related techniques are most often limited to BICS-like practice, and quite a large portion of everyday communication requires some form of analytical and/or assessmentlike involvement (i.e. the activities that are largely positioned within HOTS), such learners are obviously being kept from doing what they should have been doing, that is learning L2 for their own, and not the teacher's sake. This seems to be the largest fallacy of frontal teaching: not only are learners given little help in their personal L2 development, but also they are often falsely convinced that their context discovery is limited externally, as it should serve to secure their school grades and not their own levels of language proficiency. What often happens is that many L2 learners get so deeply entangled in the external L2 lesson demands, believing that such passive forms of lesson involvement as proposed by the teacher will suffice in helping them become

\footnotetext{
${ }^{8}$ An interesting suggestion that closely relates to the issues presented above can also be found in Webster, Beveridge \& Reed (2003).
} 
language proficient without entailing their own endeavors and preferences over the communicative competences of the language.

The form of L2 education many world L2 teaching institutions (such as TESOL, for example) focus on is based upon active implementation of the Communicational Approach. As observed by Song (2020), this type of L2 education assumes that the basic form of teacher-learner (further: T-L) cooperation ought to rest upon competently organized classroom interaction. Thus, any L2 lesson which includes interaction must not only contain the introduction and practical dissemination of many LOTS-related exercises, but also clearly focus upon the introduction of attractive and original practice of HOTS. Any form of individual involvement of either a learner, or a teacher during a lesson of this type should therefore include exercises where the learners' personal opinions, assessments and/or many other forms of linguistic productions, together with clear personal involvement in the topic is essential. Presentation of one's synthetic, analytic and/or evaluative forms of involvement are in this way recognized as the fastest and didactically the best forms of upgrading language proficiency. While being involved in an activity of this type, not only does one have to pay attention to what is called language means (Repka \& Šipošova, 2017), such as pronunciation, grammar, vocabulary and discourse, but also to a number of cognitively-marked forms of semantic analysis. What expressions (not, necessarily the ones found in the learners' course-book) can be used in a given communicational situation? Why are these phrases more semantically fitting than others? What could be the most functional presentation of a given evaluative idea? Which forms of topic illustration most closely embrace the assessment just born in the learner's mind? All these, and many other similar questions, are to be answered in just a fraction of a second, empirically tested in an on-going talk and stored in the learner's long term memory (further: LTM) as appropriate patterns of use.

Naturally, many interaction-entailing classroom activities can be carried out in any of the four context-related situations mentioned above. Following Komorowska (2006), when the learners notice the teacher's reactions to what is being read, said, listened to or spoken about during a lesson they are able to follow many non-verbal forms of behavior. The students usually gain additional information closely connected with the context a given message contains by listening to the tone of voice, observing body movements, facial expressions and not even knowing or being aware of the fact that they are doing so. Said message can either be a context-embedded, or a context-reduced form of presentation, which is being delivered in either a cognitively demanding, or cognitively undemanding situation. A typical example could be a conversation about a story heard on the radio, or while listening to an MP3, a CD, a film watched on TV, or with the help of video equipment, a discussion concerning a story read in a book (either in the classroom, or as a form of homework) or any other classroom-organized, classically presented form of listening comprehension. Any whatsoever analysis of the registers, tone or stress changes etc., found in a dialogue are not merely good but educationally necessary context training focusing forms of L2 education. L2 students, by being required to enter the areas of LOTS/HOTS activity, are, at the same time, given a 
chance to practice (and, subsequently, store any of the ready to internalize patterns) various interaction (as well as context recognition) demanding situations (Polok, 2020) .

\section{DISCUSSION}

All the quests presented above should bring us to the issue of lesson design which, as it seems, remains one of the most basic duties/responsibilities of the teacher. Following the outlines of a language lesson offered by Richards and Rogers (2010), one of the most important as well as creatively-oriented forms of teacher involvement is the component labeled lesson design. Baker (1997) stresses the fact that any L2 lesson plan should not only consider the actual level of TL fluency possessed by its participants, but also the forms of presentation L2 learners are willing to accept. Accordingly, Baker (1997), states that L2 teachers are to pay utmost attention to whether or not the context which is to be presented during a lesson, will eventually be 'digested' by the learners 9 . Naturally, as one can see, it is here where Baker turns his analytic eye upon the forms of context, actually being delivered to the learners. The issues of context embeddedness (or reduction) do have an impact; any learner, not fully trained to detect, search for, find, follow and/or understand the context, will primarily not accept (or feel disappointed with) the lesson they have participated in. Unfortunately, unforeseeable problems, to appropriately discover and/or comprehend the context in a given text/message do occur and must be addressed/explained. After all, the issues of lesson meaningfulness are to be decided on and evaluated by the learners, who in this way take responsibility for the degree of success or failure in acquiring language proficiency ${ }^{10}$.

It is also worth remembering that any learner who ignores evident signals that $\mathrm{h} / \mathrm{s}$ has problems with the discovery and/or comprehension of the lesson's reading context will not be able to learn much, if anything at all. Feng (2000) observes that in making an involuntary assessment of the lesson, many learners will most probably recognize it as a waste of time and - if psychologically not fully prepared to face such a situation - leave the classroom with a bitter feeling of failure. This is, mostly, why the relevance of curriculum, both for a learner and a teacher, as well as the relevance of each of the lessons designed on the grounds of such a curriculum, appears to be so important not only for the issues of learner-related topic internalization, but also for the outward issues of mutually beneficial co-existence of both the learners and the teacher during the lessons.

\footnotetext{
${ }^{9}$ A similar, although not outwardly stated, approach can be observed in Feuerstein, when he formulates the three basic principles of a good lesson: lesson significance for a learner; learnerassessed future lesson relevance; as well as teacher's and learner's shared intention in respect to the lesson just delivered (see: R. Feuerstein, Y. Rand. M. Hoffman \& R. Miller, (1980), Instrumental Enrichment, Glenview, Ill : Scott Foresman; M. Williams \& R. Burden (2005), Psychology for Language Teachers, Cambridge : Cambridge University Press)

${ }_{10}$ An interesting opinion on the topic can be found in the analysis of the experiment carried out by Reid (2012) in: (Pokrivčakova, 2012)
} 
In many schools the curriculum is usually presented to a teacher in the form of biblicallike phenomenon. In other words, as many teachers report, they are quite often informed that the demands sketched in the curriculum are to be adhered to regardless of the oncoming situational conditions (Werbińska, 2016). Teachers are also obligated to transfer the compulsory amount of curricular knowledge into the individual cognition of each of the learners. There are obviously no exceptions to this stringent rule, which must be accepted and put into action; thus strictly speaking, the declarative demands appearing in the curriculum are to be scrupulously followed.

Nevertheless, an FL teacher is also expected to create a syllabus, where $\mathrm{h} / \mathrm{s}$ is advised to catalogue the order in which the required linguistic structures and vocabulary included in the curriculum is presented. Thus, a syllabus, produced by a language teacher, should entail the knowledge earlier found in the curriculum, although the teacher is given leeway to propose the means by which this knowledge (both declarative and procedural) is to be transferred to the learners. Obviously, many teachers do take a shortcut here; instead of laborious invention of how to deliver the prescribed amount of knowledge to the learners, they quite often accept the propositions contained in the teacher's coursebooks; as research shows (cf. Wenden, 1998; Griffiths, 2003; Anderson, 2005; Scrivener, 2010), not all learners are able to blindly accept (and follow) such procedures. What quite often takes place is a growing feeling of disappointment in the learners who cannot skillfully follow the expectations imposed upon them, as in many cases, the proposed course-books clearly prefer accuracy-oriented activities. As a result, many learners are convinced that the primary reason for learning a foreign language means being proficient in appropriate recognition (as well as subsequent application) of various linguistic structures, with a feeling that interactive communication (i.e. the reason why most of them have started language education) is to come later (the adjective later, meaning some unspecified time in the future).

Consequently, in attempting to design a syllabus, many language teachers seem to forget about (or, at least put less importance on) the leading function of context. As previously mentioned, a foreign language learner should come to the conclusion that most of the text-related context is largely dependent upon many intermediary activities. In recognizing the ways of BICS functioning, i.e. the situations which are largely contextembedded offer a chance for the language learners to get accustomed to being guided and openly informed about how to search for, find and make use of the said forms of context. However, apart from the situations where context discovery can be grasped as easily as ABC, there should also be lesson activities where (spoken or textual) context is reduced; such lessons, in this way or another, ought to prepare the learners to find, comprehend, internalize and function in a variety of differing context-embedded situations, as such cases will certainly help the learners discover different forms of context existence as well as prepare them to function appropriately in unbounded contextual communication in the future. SL exercises such as; reciting poems of various type and kind, relating the course-book situations to existing knowledge, listening to the information delivered with the invaluable aid of aural means (e.g. an MP3 or CDplayer), paying attention to various styles and/or conventions is likely to enable FL learners to recognize and actively follow the context provided in a largely reduced 
manner. Therefore, as Bernstein (1972), or Komorowska (2006) indicate, learners are expected to be involved in the practical aspects of various verbal planning activities, that is to effectively apply any of the oral procedures of: orientation, selection and organization specified by him (as well as other academics ${ }^{11}$ ). It is with the help of these practical skills that the learners are encouraged to get involved in the interaction process observed both in and out of the classroom.

Naturally, there are many aspects (placed both outside and inside the classroom) that influence internal shaping and development of the process of context recognition (Widdowson, 2000). Robson (1995) states that, what a teacher can usually build on while delivering a lesson are individual learner strengths, such as knowledge, understanding and experience. In other words, it is a learner who is primarily responsible for the ways $\mathrm{h} / \mathrm{s}$ gets involved in context search; it is the teacher, however, who is responsible for the whole process of facilitating learners' attempts to discover and appropriately grasp the context. Should a teacher who - while practicing the skill of listening with intermediate learners, still allow students to have open course-books with the listening scripts in front of them? Will the learners be appropriately prepared to feel competent and relaxed enough to take part in real context-reduced situations in outof-the-classroom conversations? Could a teacher, who keeps the learners chained to accuracy-oriented situations (where the context is always at hand), be relatively certain that these forms of context recognition will truly help the learners feel less anxious concerning their fluency in real time communication? What seems to be indispensable to FL learners during a language course are such L2 lessons where, among others, the syllabus design is obligatorily in accordance with a number of issues, such as: $/ 1 /$ the learners' past and present educational experience; $/ 2 /$ comparative focus on the learners' native/target culture; /3/ "entry skills" (Baker, 1997, p. 156), necessary for a task to be completed; /4/ the means by which information is presented to the learners (with/without other aids, for example); and, last but not least, /5/ clear learner-friendly forms of (commonly applied) formative assessment, offered to and by the learners (so as to make students more autonomous and less dependent on teachers). As it seems, these are without a doubt indisputable concepts that L2 learners expect to find in any FL syllabus, if context is to be one of the focused-upon forms of classroom activity. Any and all linguistic progress/achievements L2 learners might have made should therefore be approached and evaluated through a wide spectrum of his/her authentic involvement in classroom activities. It is only in such all-encompassing conditions that language learners may develop into fluent language users (Lee \& VanPatten, 2003).

As indicated by Frederickson \& Cline (1990), what is to be observed first and foremost in language lessons is the learners' interest in the language e.g. its speakers, culture and

\footnotetext{
${ }^{11}$ An interesting elaboration of the topic can be found in the work by B. MacWhinney \& $\mathrm{H}$. Osser, (1977). Verbal planning functions in children's speech. Retrieved from: http://repository. cmu.edu/psychology (accessed 05.03.2018). Similar approaches can also be found in Hadley (2000), Yamin-Ali (2010), or Liu (2015).
} 
traditions etc. It is a commonly known truth that any lesson during which the learners have not shown or developed an inquisitive interest in, has to be deemed insufficient or as actually having missed the point. The process of message internalization always expects a learner to accept and consider the information presented as useful, necessary and logically fitting into any of his/her previously gained bits of knowledge. If such conditions are not met, most of the message confined knowledge stagnates. The learner seems to remember the context and even knows how to manipulate it, but after $\mathrm{h} / \mathrm{s}$ has stopped actively using it for a couple of days (or weeks), all the seemingly easy access to knowledge content simply vaporizes/disappears (Fischerova, 2012 quoted in Pokrivčakova, 2012). Even if the learners start revising the previously understood messages and structures once again, in most cases they appear to be either new, or rediscovered and evidently need to be re-analyzed (or even re-studied) from the beginning (ibid.). Whether such learners come to the same conclusion/s/ they had earlier i.e. the first time round, or whether they can move further (in this way discovering a slightly different logical concept) obviously depends on the forms of re-analysis applied.

And all this happened, mostly because the teacher had not directed enough appropriate attention to the presentation of the introduction of message-related context. In many cases, a supposition that it is the learners themselves who should be able to discover and internalize the context comes to mind. Generally, this notion prevailed in the over-all picture of the lessons designed by the teacher, the fact that the learners may have problems with appropriate context discovery did not even pass through his/her mind (Werth, 1999). The forms, the techniques of topic presentation and the procedures used to get the learners to 'see the point', seemed so easy and convincing to the teacher that $\mathrm{h} / \mathrm{s}$ had simply overlooked the fact that there may still be learners who need longer periods of time and more practice with the topic, or who, as Gardner (2004) claims, are simply of a different type of learning ability/talent.

Apparently, both the lesson syllabus and, primarily, the curriculum it refers to, ought to be seriously reconsidered as to the importance of context in the entire process of language education. There are at least two reasons for this form of treatment; the first refers to the process of individually woven lesson design and embraces the ways a teacher genuinely wishes to draw the learners' attention during the lesson. The second one is largely placed within the learners' response to what the teacher has prepared for them and includes both the affective and sociological reactions to the teachers educative proposals. As both of the reasons are of utmost importance to the process of FL education, it seems necessary to have a closer look at each of them in turn/separately (Polok, 2014).

In delivering any kind of information to the learners, a teacher is to remember that it should be clear and moderately easy to comprehend, logically sketching the general ideas that relate to the lesson topic. Nonetheless, a learner who has not been able to grasp the content during his/her first endeavor, quite often simply gives up and considers any further attempts to be useless. This is why both the individual "philosophy" of what teaching a foreign language is for a teacher as well as the general picture of a lesson design and the adjoined, explanatorily sharpened, lesson procedures must never leave 
the question of context without an in-depth clear-cut clarification of the ways in which the lesson is to help learners discover the language (Bieńkowska \& Polok, 2020).

As aptly observed by Richards \& Rogers (2010), what a lesson offers has to meet the learners reciprocal expectations, if not, the lesson will be negatively assessed by the learners and relegated to a place in memory as a lesson where nothing useful, spectacular or positively motivating happened ${ }^{12}$. What usually decides where to place such a lesson are the proposals of educational behavior the learners have found (and experienced) in many other lessons. It has to be remembered that, while taking part in a language lesson, all learners expect to find a way which will enable them to produce different communicative messages in as an unhampered and efficient way as possible. Consequently, the issue of context is usually validated by the learners. Are the learners able to consciously put forth their thoughts using expressions naturally belonging to the L2 or do they still have to nervously search for the equivalent words/phrases, thus, making incomprehensible semantic compromises which in turn bring about negative feelings of disillusioned communicative reality? Are the learners able to produce sentences which truly encompass everything they have wanted to inform others about?

Partly, in order to counteract such unwelcome motivation extinguishing situations, the lessons offered ought to be streamlined to the learners' level of natural, acquisitionbased context comprehension, thus, stimulating the learners to further work on the one hand and also soothing agitation on the other. A wise, slogan-like stance states that easier tasks ought to precede more demanding ones which could be modified to mean that context-embedded activities should come before any contest-reduced ones. Consequently, following Robson (1995), or an elaboration of his idea proposed by Bieńkowska \& Polok (2020), who propose ways of selecting the forms of FL communication to be offered to learners in the classroom (or when dealing with underachievers), an exemplary lesson should begin with preferred activities that base upon cognitively undemanding communication, paired with easily discovered elements of context. It is only after the learners have mastered how to skillfully search for a slightly reduced context, that more demanding pieces of information containing deeply reduced context could be proposed. The following examples offered by Baker (1997) are also quite convincing; talking about the elements easy to demonstrate with evident and strongly applied TPR components, or extensive use of either the blackboard or, whenever possible, the IWB, may positively influence the level of the learners' involvement in the lesson and make them less skeptical as to their linguistic abilities.

Additional evidence can also be found in numerous research reports which focus upon the particulars of the application of selected FL teaching methods. It was, for example, reported (Pinner, 2013) that appropriately organized motivation-triggered stimuli undoubtedly assist, encourage and improve the FL learners concentration on selected communicational topics and thus follow the desired context of the intended talk or exercise. Younes (2016) also discovered the beneficial influence of outdoor activities on

\footnotetext{
${ }^{12}$ See also a very useful elaboration by P. Takavoli and R. Jones (2018).
} 
the educational processing and simultaneous growth of ease in context-directed talks when delivering CLIL lessons. Both examples clearly indicate the importance of circumstantial context as labeled in Mathews' (2014) dictionary.

Similar issues have been noted by Bollas (2018) in a paper advocating the necessity of teaching context recognition to FL learners. In his opinion, what an FL teacher is never to overlook is the learners' attitude to the topic that is being dealt with; said attitudes are often considered as either reluctant or even topic/text negative. One of the reasons for such an approach may be a learner's conviction that a given text is too difficult due to an excessive number of expressions assessed as either unknown or too weirdly placed to allow the learner to swiftly and effortlessly comprehend a topic/text. As Bollas (2018) claims, one of the fallacious reasons for such an attitude is a commonly prevailing belief that a text is deemed comprehensible and appropriate to work with when all the phrases, expressions, and/or words found there can be understood (Bollas calls this situation 'lack of tolerance of ambiguity'). As one can easily see, such lack of tolerance of ambiguity strongly impinges the process of textual (as well as situational) context analysis, thus, discouraging learners from proceeding with any whatsoever activity that may help them embrace the context-based information. A solution offered by Bollas (2018) is to modify and individualize the whole text for each of the learners by means of adding a limited number of nonsense words, in this way changing it into a game, or some other communication-aimed activity. The idea behind said approach is to teach learners the functions performed by the words in a sentence; such an activity should allow the learners to discover the fact that each of the words appearing in a sentence is there in order to fulfill an informative function ascribed to it by the sentence order itself. Having discovered the reasons why the words/phrases are in specific sequence, the learners should be able to grasp the sense of a general connection of the words, as well as their mutual co-operation to produce the hypernymic tissue of context.

Primarily, the notion of the function each of the words/ phrases has been designed to perform was also observed by Nuttall (1996). One of, as Nuttall (1996) claims, the important issues in the process of FL education is to teach the learners to look for, discover and put together text-hidden information clues, so as to be able to reconstruct semantic pictures hidden in the text. It is in looking for such clues and assessing their usefulness for reconstructing the initially inferred semantic picture that generates internalization of context-related messages. In Nuttall's (1996) opinion, no learner will be able to swiftly follow a text when $\mathrm{h} / \mathrm{s}$ has not been able to implement this obligatory/canonical educational skill. In this way, partly echoing her claim, one can say that a learner will not manage to discover the sense of a context hidden within a text before mastering the process of functional adjustment of each of the words found in a text (written or spoken).

A handy example, just to graphically illustrate the educational steps taken to help the learners, might be offered here (Acton, 1979): while practicing the target language (further: TL) in the classroom, a teacher might offer a number of various procedures so as to make the learners more sensitive to certain TL peculiarities. Thus, in making an attempt to explain the ways tense functions, one may offer such procedures as: /1/ asking 
the learners to look up the definition presented in the course-book and to memorize the scope of tense use specified there; /2/ instructing the learners to find the scope of tense use by analyzing the examples found in the course-book; /3/ orally explaining the way a tense is used with its subsequent graphic presentation on the blackboard; /4/ contrasting an example of said tense use with other tenses on the blackboard; or $/ 5 /$ when tense use has been explained, asking the learners to search for similar examples of use in a paragraph or reading comprehension text contained in the course-book. Obviously the issue of context differs in each of the forms of teaching presented above. While the context is largely embedded in either $/ 3 /$ or $/ 5 /$, it remains partly reduced in $/ 2 /$ and largely reduced in $/ 1 /$ and $/ 4 /$. Also, the inherent situations of context presentation differ, moving from cognitively undemanding in $/ 3 /$, to cognitively demanding in $/ 1 /$. In this way, one may expect various levels of explanatory output, which evidently remain in close dependence on individually-shaped, current levels of language proficiency. The learners, who are clearly field independent and whose level of language proficiency is at least moderate, will most probably be able to respond in a more comprehensible way, in contrast to many less proficient and field dependent learners, who simply need a situation revealing far more context embedded educational conditions (Bieńkowska \& Polok, 2020).

Nonetheless, the aforementioned teaching procedures concern context issues in which one can see the relevance of the curriculum and its close connection with the ways topical context is presented to the learners. As a syllabus is always expected to link the curricular indications in many ways, it is necessary to offer a curriculum, more closely observing the many individual differences that may occur among the learners. Apparently, this is usually necessary because many (mostly beginning and inexperienced) language teachers are not always able to recognize the current needs of their learners, thus, basing their syllabi on the course-book contents, where the notion of topical context is not always stressed. Such a situation is, in many cases, a result of both the course-book author's and the publishers' assumptions that appropriate presentation of lesson contents by the teacher is more than obvious, which is not always the case. As FL education is assumed to be a continuous process, what is naturally expected are many returns to the portions of knowledge presented some time earlier e.g. many knowledge loops constructed in a deliberate and conscious way both explicit and implicit, conscious application of the learners' cognition in ways recognized as obviously helpful in the process of language discovery. This is why the teacher has to become an attentive and scrupulous reader of the information possibly found in either the core curriculum, or any other curricula recognized as obligatory to meet the outcomes of some, particularly specified, forms of language education. When such issues have been overlooked, the whole process of language education must be either produced in a much slower manner (which appears to be a form of rule breaking by such teachers), or in a way that does not focus enough appropriate attention to the intrinsically inherent individual differences which are likely to appear when teaching a group of learners. 


\section{CONCLUSION}

Following the multi-layered definition of context, offered by Ruedel, Brann, Grey \& Zorfass (2013), the issue of context performs a most important function in the whole process of FL education. Not only is it to be observed from the linguistic ways of a message analysis, but it also matters when the very psychological process of language education is being looked through. When making an attempt to consider the many existing common teacher-learner interrelations, one cannot overlook the fact that inappropriately handled topical context usually begins the process of slower individual responses of the learners to the educational attempts produced by their teachers. Understanding that teaching topical context actually means careful presentation of all the accuracy-focusing activities that correlate with quite a number of aspects of grammatical, lexical, morphological, syntactic, semantic and/or even pragmatic nature, actually means drawing the learners' interest and attention by the production of skillful invitation to cognitively identify the similarities and/or differences that exist between the two languages i.e. the mother tongue and the target language they wish to become proficient users of. It is obviously where both "the art of language teaching and the science of learning" (Skinner, 1954 [2001], p. 106) are usually confined.

While making an assessment of the need to apply a given phrase/expression so as to illustrate the sense of thought one wishes to convey, it seems necessary to recognize the relative importance of a number of issues that belong primarily to either the circumstantial, or textual context-producing layer, or to both (Bieńkowska \& Polok, 2020). Consequently, the following issues (of both technical and/or psychical nature) should be scrupulously reconsidered:

- the function of context in the process of message construction, i.e. whether currently what matters are both forms of context to be taken into account or whether one of them overshadows the other one;

- the ways the context is to be approached, i.e. whether what the learners are primarily to get in touch with are embedded or reduced examples of context;

- the currently observed attitude of FL learners to the texts dealt with during lessons, i.e. whether any symptoms of text-connected anxiety can be detected, or not;

- the principal aims of a lesson, i.e. whether what is to be primarily focused upon is textual (comprehensive) analysis only, or whether semantic text analysis has been planned as well;

- the design of a lesson, i.e. to determine whether what learners are to do during a lesson is closer to accuracy-oriented, or fluency-oriented activities;

- the general idea of interactive activities a lesson has been rested upon, i.e. whether what is being aimed at is communication (understood as practice in individual production of messages), or text-based communicative production 
(understood as reproduction of information stored in a text, together with the application of as many handy expressions as possible);

- last but not least, the philosophy of language use, i.e. whether the language being dealt with is to suit the individual needs of a learner, or whether its principal aim is to satisfy the requirements imposed on a learner such as (scoring a good grade, for example);

In all the aforementioned issues, as well as in many others not mentioned in the list above, the function assumed by any form/type of context seems to be of primary importance. It not only allows learners to grasp the semantic scent of meaning accumulated in a sentence, or a passage, but also lets the users reflect on and discover mutual (helpful) bonds that exist between semantics and syntax. While analyzing the construction of a sentence one has to be effectively trained to search for and perceive the clues that would satisfactorily meet presupposed expectations as to the semantic shape of a message a learner-reader/listener has been able to produce and, in this way, proving and reaffirming the recipient's sketched assumptions. Learners unaware of the proper organization of the distribution of message particles containing semantic clues are usually unable to reconstruct the whole semantic picture offered in a textual or oral way. One needs practice to make use of the inferring procedures that may function as effective helpers in a process of such semantic construction. This is why one of the issues to be particularly stressed during the whole process of FL education is the scrupulous and sensible introduction of a learner into hidden semantic inferring sentence-based activities. As observed by Bieńkowska \& Polok, (2020), a learner, who feels uncertain will usually see him/herself as a person expected to do a 'must-be' activity, which is an activity belonging to a group of external routine procedures. As a result, his/her attention is focused upon mechanical reproduction of the LOTS-related sense-hidden discovery processing of a passage (or even the whole text), which effectively turns him/her away from the natural HOTS-focusing search for the meaning. What often appears in such situations is not only less motivation to practice the language being learnt, but also a gradual decrease in the learner's positive attitude towards the language as such. After all, the so-called false beginners are not fictitious beings, are they?

While looking into Bernstein's (1972) scientific heritage one can find a very interesting analysis of a linguistic verbal planning process as perceived by readers/listeners. The whole process is split into three autonomous sections (or procedures): the ones of orientation, where people look for dominant signals in received information, the ones of selection, where the received dominant signals decide on the elements of the language included in the answer; and the ones of organization, where the selected elements are fitted in the recipient's system of grammar, primarily observed in his/her native tongue. Briefly speaking, when making an attempt to participate in a verbal/nonverbal interaction one has to be able to recognize the nature of a message, as this is an introductory step to safely rest an answer upon. However, the very process of message recognition has to include information of both structural and semantic nature (Komorowska, 2006, Pokrivčakova, 2013). The knowledge that relates to the structural 
material requires one to differentiate between content words and 'glue' words (Garner, 2001), that help content words function properly. At the same time, one's knowledge of what a given word/expression means is somewhat completed with the information supplied by internal syntactic rules, smoothly correlated with earlier semantic data. Therefore, it is one's knowledge of the procedures applied to effectively recognize textual context, when added to the external circumstantial context data, that produces a completed process of message reception, and initiates a simultaneous process of return message production. Knowing who said something (external context), as well as what the contents of the written/spoken message referred to, helps one to produce an appropriate answer which has to suit both the internal and external conditions a given story/message has taken place in. After all, when everything is said and done, essentially, it is interpersonal communication that FL lessons are all about!

\section{REFERENCES}

Acton, W. (1979). Second Language Learning and Perception of Differences in Attitude. In Culture Bound. In: J. M. Valdes (ed.) Cambridge : Cambridge University Press;

Anderson, L., \& Krathwohl, D. A. (2001). Taxonomy for Learning, Teaching and Assessing: A Revision of Bloom's Taxonomy of Educational Objectives. New York: Longman.

Anderson, N.J. (2005). L2 learning strategies. In: E. Hinkel (ed.) Handbook of research in second language teaching and learning. Mahwah, NJ : Lawrence Erlbaum Associates;

Baker, C., (1997). Foundations of Bilingual Education and Bilingualism, Clevendon : Multilingual Matters;

Bentley, Kay (2010), The TKL Course. The CLIL Module. Cambridge : Cambridge University Press;

Bernstein, B. (1964), Elaborated and Restricted Codes: Their Social Origins and Some Consequences. In: Smith, A. G. (ed.), 1966, Communication and Culture, New York : Holt, Rinehart and Winston;

Bernstein, B. (1971). Class, Codes and Control: Theoretical Studies Towards a Sociology of Language. London: Routledge \& Kegan Paul;

Bernstein, B. (1972). A socio-linguistic approach to socialization with some reference to educability. In J. Gumperz \& D. Hymes (Eds.), Directions in sociolinguistics. New York: Holt, Rinehart \&Winston.

Bieńkowska I. \& Polok, K. (2020). Construing Foreign Language Education. Radom : INW 'Spatium' (in print);

Bollas, A. (2018) Using Context to Infer meaning. In: English Teaching Professional, 118, pp. $14-16$; 
Connor D.J., Gabel, S. L., Gallagher D. J. \& Morton M. (2008). Disability studies and inclusive education - implications for theory, research, and practice. In: International Journal of Inclusive Education, 12/5-6 Retrieved from https:/www.researchgate.net/ publication/254797270_Language_education_in_Europe_The_Common_European_Fra mework_of_Reference (Accessed: Oct. 10th. 2020)

Cummins, J. (1984). Bilingualism and Special Education: Issues in Assessment and Pedagogy. Clevendon : Multilingual Matters;

Cummins, J. (2008). BICS and CALP: Empirical and Theoretical Status of the Distinction. In: Street, B. \& Hornberger, N. H. (Eds.). (2008). Encyclopedia of Language and Education, 2nd Edition, Volume 2: Literacy. (pp. 71-83). New York: Springer Science + Business Media LLC

Duval. S. \& R.A. Wicklund (1972). A Theory of Objective Self-Awareness. New York \& London : Academic Press;

Feng L Ch, (2000). Context and Context Teaching. In: Foreign Language, 4, pp. 33 -37;

Fischerova, Z. (2012) Experiment in Vocabulary Acquistion and Development Research, In: (S. Pokrivcakova, ed.) Research in Foreign Language Education, Brno : MSD, pp. 193 - 224;

Frederickson. N. \& T. Cline (1990). Curriculum Related Assessment with Bilingual Children. London : University College London.

Gardner. H. (2004). Frames of Mind. The Theory of Multiple Intelligences. New York : Basic Books.

Garner, B A. (2001) Legal Writing in Plain English. A Text with Exercises. Chicago: The University of Chicago Press.

Garside, T. (2019) The importance of Context for English Teaching: Experience, Situation and Surrounding Language In: The EfA Blog - TESOL https://hongkongtesol. com/blog/2019/05/ importance-context-english-teaching-experience-situation-andsurrounding-language

Griffiths, C. (2003) Language Learning Strategy use and Proficiency. Retrieved form: http://www.umi.com./umi/dissertations/ (Accessed 02. 02 2017).

Hadley, O. A. (2000). Teaching language in context (3rd ed.) .Boston, MA: Heinle \& Heinle.

Halbach, A. (2003). Exporting Methodologies: The Reflective Approach in Teacher Training. In: (M. Byram \& P. Grundy, eds). Context and Culture in Language Teaching and Learning, pp. 51 - 58. Clevendon : Multilingual Matters, Ltd.

Kębłowska, M. (2002). The role of the foreign language teacher in the classroom-The teachers' beliefs and role behavior versus the students' expectations. In: Studia Anglica Posnaniensia, 37, pp. 318-327. 
Komorowska, E. (2006). Intercultural Competence in ELT Syllabus and Materials Design. In: Scripta Neophilologica Posnaniensia, Tom VIII, pp: 59-81;

Kramsch, C. (2003). From Practice to Theory and Back Again, In: (M. Byram \& P. Grundy, eds). Context and Culture in Language Teaching and Learning, pp. 4 - 17. Clevendon : Multilingual Matters, Ltd.

Krashen, S. 1981, Second Language Acquisition and Second Language Learning, Sacramento, Cal.: Pergamon Press, Inc.

Krashen, S. \& Brown, C. L. (2007), What is Academic Language Proficiency. In: Research Papers, pp. 1 - 4; Retrieved from: www.joanwink.com/ newsletter2007/ Krashen-Brown-ALP (Accessed: Oct 10, 2020).

Lee, J. F. \& VanPatten, B. (2003). Make Communicative Language Teaching Happen. Boston: McGraw-Hill.

Levine, G. S. (2010). Code Choice in the Language Classroom. Bristol : Multilingual Matters.

Liu L. (2015). On Context Theory and Interactive Language Teaching. In: International Journal for Innovation Education and Research, 3(11), 152 - 156. http://www.ijier.net

Matthews, P. (2006), Oxford Concise Dictionary of Linguistics, Oxford : Oxford University Press.

Norman, D. (1980), What goes on in the mind of the learner. In: Learning, Cognition and College Teaching.(ed. W. McKeachie), "New Dimensions in Teaching and Learning”, San Francisco : Jossey-Bass [vol. 2], pp. 37 - 48.

Nuttall, C. (1996), Teaching Reading Skills in a Foreign Language, London : Heinemann;

Online dictionary. Retrieved from: http://www.dictionary.com/browse/context (Accessed: 21.02.2018).

Pinner, R.S. (2013). Authenticity and CLIL: Examining authenticity from an international CLIL perspective. In: International CLIL Research Journal 2(1), 44-54.

Pokrivčakova, S., (2012) Latest Developments in Foreign Language Research in Slovakia. A General Overview. In: (S. Pokrivcakova, ed.) Research in Foreign Language Education, Brno : MSD, pp. 9 - 28.

Pokrivčáková, S. (2013), Modern Teacher of English, Nitra: ASPA.

Polok, K. (2014) English as An International Vehicle: A Glottodidactic Approach, Nitra: ASPA

Polok, K. (2018) Quiz Yourself! A Collection of Not-Very-Boring Lingusitic Activities: Introduction, Beau Bassin : LAP Lambert Academic Publishing. 
Reid, E. (2012) Observation in Foreign Language Pedagogy Research. In: (S. Pokrivcakova, ed.) Research in Foreign Language Education, Brno : MSD, pp. 29 - 61.

Repka, R., M. Šipošova (2017), Communicative Approach and the Teaching of English Language Means to Slovak Learners. Bratislava : Z-F Lingua.

Richards, J. \& Rogers, T, (2010). Approaches and methods in language teaching, Cambridge : Cambridge University Press.

Robson, A. (1995). The assessment of bilingual children. In; M.K. Verma, K.B. Corrigan, \& S. Firth (Eds.), Working with bilingual children: Good practice in the primary classroom. Clevedon, England: Multilingual Matters.

Ruedel, K., Brann, A., Gray, T., \& Zorfass, J. (2013). Technology implementation practice guide: A school-wide approach to PowerUp teaching and learning. Washington, DC : American Institutes for Research.

Skinner, B. F., 2001 [1954]. The science of learning and the art of teaching, In: A. Pollard (ed.), Readings for Reflective Teaching, London: continuum.

Song Bao'e (2020). The Research on Effectiveness of Communicative Language Teaching in China. [in:] Asian Culture and History; Vol. 11, No. 1. pp. 1 -10.

Song L., (2010). The Role of Context in Discourse Analysis. In: Journal of Language Teaching and Research, 1(6), 876-879.

Takavoli, P. \& Jones, R. (2018) An Overview of approaches to second language acquisition and instructional practices. Cardiff : Welsj Government Report Number 12/21018. Retrieved from http://gov./wales/statistics-and-research/overview-approaches -and-second-language-acquisition-instructional-practices/?/lang=en Access: 12/10/2018

Webster, Alec, Michael Beveridge \& Malcolm Reed (2003), Who holds an initiative in classroom interaction? In: ( A, Pollard, ed.) Readings for Reflective Teaching, London : Continuum, pp. $248-251$.

Wenden, A. L. (2003). Metacognitive knowledge and language learning, Applied Linguistics, 19, 515 - 537.

Werbińska, D.. (2016) Learning from Retired Language Teachers' Biographies: A Research Proposal. In: Pawlak M. (ed.) Classroom-Oriented Research. Second Language Learning and Teaching. Springer, Cham. Retrieved from: https://doi-org443.webvpn.zisu.edu.cn/10.1007/978-3-319-30373-4_4. (Accessed, Oct 10th, 2020).

Werth, P. (1999). Text Worlds: Representing Conceptual Space in Discourse. London: Longman.

Widdowson H.G. (2004). A History of English Language Teaching. 2nd Edition. Oxford : Oxford University Press.

Yamin-Ali, J. (2010) "Context" - The Magic of Foreign Language Teaching. In: Caribbean Curriculum. Vol. 17, pp.17-32. 
Younes, M.I.A. (2016). The Impact of CLIL on Arabic, English and Content Learning of Arab High School Students in the UAE (unpublished MA dissertation). The American University of Sharjah. 